\title{
Facile Synthesis of Hierarchical MnO@C Nanoplates for High- Performance Lithium-Ion Batteries
}

\author{
Chaochun Yuan ${ }^{1}$, Kun Wang ${ }^{1}$, Huanhuan Li $^{1}$, Yaping Wang ${ }^{2, *}$, Long Chen ${ }^{1}$, Haobing Jiang ${ }^{1}$, \\ ${ }^{1}$ Automotive Engineering Research Institute, Jiangsu University, Zhenjiang 212013, P. R. China. \\ ${ }^{2}$ School of Material Science \& Engineering, Jiangsu University, Zhenjiang 212013, P. R. China. \\ *E-mail: wangyaping@ujs.edu.cn
}

doi: $10.20964 / 2017.06 .43$

Received: 9 March 2017 / Accepted: 18 April 2017 / Published: 12 May 2017

\begin{abstract}
A facile strategy for synthesis of hierarchical $\mathrm{MnO} @ \mathrm{C}$ nanoplates has been developed via one-step pyrolysis of Mn-glycolate coordination polymers. Core-shell MnO@C nanoparticles with ultrasmall sizes as the primary building blocks are interconnected to construct porous nanoplates. The unique architecture is favorable for the fast diffusion of lithium ions and electrons, accommodating the volume change of $\mathrm{MnO}$ during the lithiation/delithiation process and alleviating the side reactions on the interface between $\mathrm{MnO}$ and electrolyte. As a result, these hierarchical $\mathrm{MnO} @ \mathrm{C}$ nanoplates exhibit fascinating $\mathrm{Li}^{+}$storage performance such as high reversible capacities, good cycling stability and rate capability when served as an anode material for lithium-ion batteries.
\end{abstract}

Keywords: MnO; Nanocomposite; Anode material; Lithium-ion battery; Energy storage and conversion

\section{FULL TEXT}

(C) 2017 The Authors. Published by ESG (www.electrochemsci.org). This article is an open access article distributed under the terms and conditions of the Creative Commons Attribution license (http://creativecommons.org/licenses/by/4.0/). 